\title{
No limite do silêncio: \\ a cena mínima de Samuel Beckett
}

Fernando Mesquita de Faria

UNILA

\section{Resumo}

$\mathrm{O}$ artigo pretende demonstrar, por reconhecimento, a apropriação do silêncio na dramaturgia de Samuel Beckett. As múltiplas funções e as possibilidades de articulação dramatúrgicas tornam o silêncio tão importante quanto os sons e seu estudo passa a ser essencial para compreendermos os aspectos sonoro-musicais que envolvem a obra do autor, sobretudo por virem associadas a uma linguagem verbal. A estrutura elíptica das suas peças, a exploração sonora de palavras e frases, a escassez de cenários e objetos cênicos, somados ao silêncio, podem produzir um efeito sinestésico no leitor/ espectador e são indícios que nos levam a uma reflexão, servindo como álibi para melhor decifrarmos a obra beckettiana.

Palavras-chave: Beckett; silêncio; repetição

\begin{abstract}
This article aims to demonstrate the influence of silence in the dramaturgy of Samuel Beckett. The multiple functions and several possibilities of Beckett's dramaturgy make the silence as important as the sound and their study are essential to understand the sonority and musical aspects in his theatrical texts. The elliptical structure of the plays, the sound of the words and the exploration of phrases, the lack of objects and scenery besides silence can produce an synesthetic effect on audience and are evidences for their reflection. These characteristics help us to investigate the dramaturgy of Samuel Beckett.
\end{abstract}

Keywords: Beckett; silence; repetition 
1. BERRET'TINI, Célia.

A linguagem de Beckett. 1977, pp. 55-56.

2. BECKETT, Samuel. Dias Felizes, 1976, p. 37.
Mas no coração das trevas havia o silêncio, silêncio da poeira e das coisas que nunca sairiam do lugar, se dependesse delas.

E o tique-taque do invisível relógio era como a voz do silêncio que, um dia, como a treva, também iria triunfar. E então tudo seria silencioso e escuro e as coisas estariam, finalmente, em seu lugar, para sempre. Malone meurt, Samuel Beckett

Samuel Beckett, dramaturgo irlandês, dos mais enigmáticos, soube manipular a ausência de sons e vozes para carregar sua obra de sentido. Em suas peças teatrais, o silêncio é empregado em diferentes matizes, mediante os termos "pausa", "um tempo", "um tempo longo", "um longo silêncio" ou simplesmente, "silêncio". É a ausência de ruído, o nada, o fundo mudo que isola palavras e frases, como isoladas são as suas personagens. Não pode existir sozinho, estando entre palavras ou sons, ou ainda, ilustrando imagens. Se por um lado Beckett ressalta a palavra ampliando-lhe o valor, por outro, torna o texto quase intransponível, dificultando sua decifração completa, sobretudo se estivermos interessados em uma interpretação analítica das palavras.

Segundo a pesquisadora Célia Berrettini, Beckett delega ao silêncio uma forte dose de sugestões. ${ }^{1}$ Em Happy Days (Dias felizes), peça escrita em 1961, cuja protagonista Winnie, encarcerada por um monte de terra até a cintura no primeiro ato e até o pescoço no ato dois, fala ao mesmo tempo em que executa pequenas ações com os objetos encontrados e retirados de sua "bolsa-sacola", preenchendo os silêncios com pequenas ações:

Winnie - ...nenhuma dor (procura a escova de dente) quase nenhuma (apanha a escova de dente) é isso que é maravilhoso (examina a escova) acima de tudo (examina o cabo e lê) pura... quê? (pausa) Quê? (larga a escova) Ah, sim. (volta-se para o saco) Pobre Willie (vasculha no saco) sem gosto (continua a vasculhar) para nada (tira um estojo de óculos)... ${ }^{2}$

No segundo ato, diante de um cenário árido e inóspito pela forte luz e calor sufocante, ela apenas fala, alternando palavras e silêncios e limitando-nos às rubricas, "pausa", "longa pausa" ou "um tempo", "um tempo longo", conforme a tradução adotada. No ato I de Happy Days, a rubrica "pausa”, foi encontrada 287 vezes e a notação "longa pausa", 14 vezes. No segundo ato, temos: 286 vezes a rubrica "pausa" e 17 ve- 
zes, "longa pausa”. Se considerarmos as pausas indicadas por travessões como silêncios, encontramos, partindo do início do monólogo da protagonista, cerca de 120 pausas, em três páginas e meia:

Winnie - ...Podia ser a escuridão eterna (Pausa.) negra noite sem fim (Pausa.) simples acaso, julgo eu, feliz acaso. (Pausa.) Ah, sim, abundantes favores. (Longa pausa.) E agora? (Pausa.) E agora, Willie? (Longa pausa.) Aquele dia (Pausa.)... ${ }^{3}$

Já a peça En Attendant Godot (Esperando Godot), escrita em 1947/1948, e considerada sua obra mais conhecida, inicia e termina com silêncio. As indicações de silêncio ocorrem 45 vezes no primeiro ato e 61 vezes no ato segundo, sem o cômputo de pausas.

O silêncio enfatiza a não-ação e contribui para "imobilizar” as personagens beckettianas, tornando-se imprescindível para o estudo de sua obra, assim como relevante na investigação de seus aspectos musicais. $\mathrm{O}$ artigo "O uso musical do silêncio”, do pesquisador Marco Antonio da Silva Ramos, aponta possibilidades em que o discurso musical desenvolve-se em pelo menos dois níveis diferentes, porém, simultâneos: um discurso estrutural e um discurso afetivo. Do ponto de vista estrutural, é comum em uma obra polifônica que uma ou mais vozes se calem, enquanto outras permaneçam repercutindo. Esse fenômeno pode ocorrer através de vários procedimentos de instauração do silêncio: "por corte" - quando todo o conjunto empregado se cala simultaneamente; "por filtragem" - quando parte do conjunto se cala e parte continua; "por tendência dinâmica" - quando em um "decrescendo" se estabelece uma tendência dinâmica al niente. A retomada sonora também está sujeita a classificações: "por corte" - quando uma grande massa do conjunto empregado no discurso ataca ao mesmo tempo; "por adição" - quando as vozes do conjunto vão atacando uma após outra, paulatinamente; "por tendência dinâmica" - quando em um "crescendo" se estabelece uma tendência dinâmica al niente. ${ }^{4}$

Em Play (peça de Beckett sem uma tradução relevante para a língua portuguesa até o momento), de 1964, o coro inicial vem sucedido pelo ataque de um novo coro, interrompido bruscamente para dar lugar a uma pausa de cinco segundos (de acordo com as informações didascálicas), assemelhando-se, desta forma, à estrutura de um silêncio "por corte":

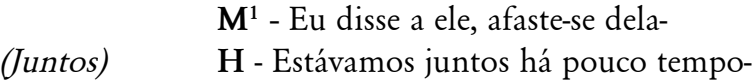
$\mathbf{M}^{2}$ - Uma manhã quando costurava- ${ }^{5}$
}

3. Ibidem, p. 82.

4. RAMOS, Marco Antônio Silva. O uso musical do silêncio, 1997, pp. 68-129.

5. BECKETT, Samuel. Play, 2000, p. 02. 
6. BECKETT, Samuel. Play, 2000, pp. 02-03.

7. Ibidem, p. 03 .

8. ROUBINE, Jean-Jacques. Introducão às grandes teorias do teatro, 2003, pp. 120-126.

9. BECKETT, Samuel. Eu não, 1998, pp. 01-07.

10. BECKETT, Samuel. Eu não, 1998, p. 02.
No passo seguinte, temos a repetição do discurso ou o desaparecimento do silêncio também de forma brusca, seguindo-se nova interrupção, mas com a continuidade da voz de $\mathrm{M}^{1}$ apresentando uma estrutura de silêncio "por filtragem":

(Juntos)

$\mathbf{M}^{1}$ - Eu disse a ele, afaste-se dela. Jurei por tudo que era mais sagrado...

H - Estávamos juntos há pouco tempo -

$\mathbf{M}^{2}$ - Uma manhã quando costurava - ${ }^{6}$

Ainda neste exemplo, podemos perceber a retomada do discurso "por adição", uma vez que, em seguida, as cabeças de Play atacam suas vozes uma após a outra, paulatinamente:

$\mathbf{M}^{1}$ - Eu disse a ele, afaste-se dela. Jurei por tudo que era mais sagrado-

$\mathbf{M}^{2}$ - Uma manhã quando costurava, ela entrou impetuosamente e veio para cima de mim. Afaste-se dele, ela gritava, ele é meu. Pelas fotografias até que não parecia tão mal. Vendo-a agora pela primeira vez, de pé, em carne e osso, compreendi porque ele me preferia.

H - Estávamos juntos há pouco tempo quando ela suspeitou de alguma coisa. Afaste-se daquela puta, ela disse, ou cortarei minha garganta - (soluça) perdão - juro por Deus. Sabia que ela não tinha nenhuma prova. Por isso, disse-lhe que não sabia de quem ela estava falando. ${ }^{7}$

O surgimento e desaparecimento do silêncio na música ainda podem ter várias funções e subfunções, conforme o artigo de Silva Ramos. Entretanto, elas não serão aqui averiguadas, em razão de Beckett propor-nos uma obra aberta e descompromissada em termos musicais, deixando tais classificações à deriva de possíveis encenações. Apesar disso, a obra do autor parece aproximar-se mais de um discurso afetivo: o "uso gestual do silêncio" ou gesto musical, classificações que apontam o momento em que a música aborda e assume discursos externos a ela.

As peças de Beckett que, em muitos casos, assumem características simbolistas, como salienta Jean-Jacques Roubine ${ }^{8}$, podem sugerir um discurso gestual, embora careçam de composições melódicas e/ou harmônicas pré-estabelecidas: os "gestos musicais dramáticos e/ou narrativos” poderiam adaptar-se a uma partitura beckettiana, pela natureza dramatúrgica. Da mesma forma, a pontuação repleta de reticências na peça $N o t I(E u \text { não })^{9}$, escrita e publicada em 1972, dá expressividade e entonação ao texto, caracterizando-o como um "gesto musical inflexional":

Boca - ... o quê?? ... quem? ... não! ... ela! ... deu consigo no escuro ... mas não totalmente ... insensível ... não ... pois ela podia ainda ouvir o zumbido ... algo como um zumbido ... nos ouvidos... ${ }^{10}$ 
O silêncio, ou ausência de manifestação sonora, tem notação própria e ocupa espaços, perfeitamente, delimitados no tempo. Não há outras variáveis além de sua duração. As funções múltiplas e as possibilidades de articulação tornam o silêncio tão importante quanto os sons. O compositor norte-americano John Cage (1912 - 1992) relata em seu livro Silence que, certa vez, entrou em uma câmara anecóica (sem eco), de onde ouvia somente dois "insuportáveis" sons: um grave, que era de seu sangue circulando pelas veias e outro agudo, do seu sistema nervoso em funcionamento. Diante disso, Cage constatou que o silêncio absoluto não pode existir, afirmando ainda que, enquanto houver humanos haverá sons e ninguém precisará temer o futuro da música. ${ }^{11}$

Mary Bryden, ex-diretora da Beckett International Foundation $^{12}$, fez um curioso comentário sobre as peças radiofônicas de Beckett ${ }^{13}$ : - "O rádio pode ser para Beckett o paraíso e o inferno. O silêncio completo é para sempre inatingível nesse meio de comunicação, mesmo um silêncio prolongado é um peso para o rádio, porque os ouvintes trocam de estação. Porém, o rádio oferece um espaço no qual som e silêncio, aliviados da interferência visual, podem ser recebidos com uma intensidade particular. Beckett distancia o ouvinte de qualquer impressão de identificação, desde que as personagens já não estejam lá. Não há nada, somente uma respiração cada vez menor e autodestrutiva”. ${ }^{14}$

Na maioria dos casos das peças teatrais de Beckett, o silêncio tem a função de fundo mudo às ações e jogos de cena das suas personagens. Seu estudo é essencial para compreendermos os aspectos sonoro-musicais que envolvem essa obra dramática, sobretudo por virem associados a uma linguagem verbal. Se as falas musicais das personagens beckettianas são imprescindíveis ao seu teatro, de igual modo é essencial nele a presença do silêncio.

De acordo com Louisa Elena Leuchs, a obra de Beckett tem forte aproximação com o Movimento Minimalista, baseando suas características em três princípios: a utilização das repetições de palavras, frases e imagens; a exposição do meio artístico; o uso do silêncio. ${ }^{15}$ Beckett inaugura a partir de Happy Days, o que podemos chamar de "teatro da imobilidade", com personagens condenadas a uma condição limitada de movimentos e a cena composta por um mínimo de imagens, entretanto, repetidas à exaustão.

Em Play, três cabeças desencorpadas habitam jarros idênticos. Homens-urnas que atuam concomitantemente como cenários e personagens, condenados à imobilidade. Em Not I é visível somente uma boca e a sombra de um ser taciturno, praticamente imóvel e de costas para a plateia. A peça impres-
11. CAGE, John. The silence, 1961, p. 08.

12. Fundação estabelecida em 1988, dentro da University of Reading, com o intuito de promover estudos e apreciações do trabalho de Beckett.

13. Beckett escreveu para rádio entre os anos de 1956 e 1963, totalizando uma produção de sete peças radiofônicas, além de uma vasta produção a partir de adaptações de sua obra literária para a televisão e para o rádio.

14. BRYDEN, Mary.

"Reflections on Beckett and Music, with a Case Study: Paul Rhy's Not I", p. 86. In Oppenheim, Lois, 1999.

15. LEUCHS, Louisa Elena. "Minimal B: Samuel Beckett and Minimal Art", 2002, p. 03. 
16. STRICKLAND, Edward. Minimalism: Origins. 1993, pp. 11, 12.

17. In LEUCHS, Louisa Elena.

"Minimal B: Samuel Beckett and Minimal Art", 2002, p. 04.

18. BRATER, Enoch. Beyond Minimalism: Beckett's Last Style, 1987, p. 35. siona pelo forte impacto visual causado com um mínimo de imagem: uma boca bocejando para o vazio e transgredindo o horizonte. O texto falado rapidamente chega ao público de forma quase incompreensível. Suas reticências reforçam o não dito, onde as palavras parecem fugir umas das outras, nunca conseguindo completar um raciocínio. O Ouvinte, a outra personagem presente na peça, faz intervenções econômicas: apenas quatro movimentos de braços que vão se reduzindo a cada manifestação. Nenhuma palavra, somente a sua audição. Entretanto a sua presença reafirma o senso teatral, proporcionando aos outros ouvintes da plateia não somente o testemunho do sofrimento da Boca, mas também, um ponto focal indispensável, no qual se pode ver a ação da peça desenrolar-se.

That Time (Aquela vez), de 1974, foi chamada por Beckett de irmã de Not I, e é similarmente concebida a partir da fragmentação da forma teatral. Uma cabeça desencarnada e as mãos suspensas em uma estrutura de palco. Três vozes pré-gravadas são transmitidas de posições diferentes, sendo a cabeça o seu próprio ouvinte. Beckett dá às palavras uma inédita presença espacial. Cada voz é a mesma voz, com uma história diferente. Portanto, o que vemos na cena beckettiana são poucas imagens reveladas com destaque excessivo ou, minimalisticamente, expostas ao extremo; o que ouvimos são orquestrações sonoras, dispostas de acordo com as imagens, porém, nem sempre em harmonia. O resto é silêncio.

Considerado por Strickland ${ }^{16}$ também um princípio minimalista, o silêncio é chamado por ele de "espaço vazio", sendo utilizado por artistas visuais para criar uma atmosfera de meditação passiva que purifique por completo a plateia. ${ }^{17}$ Há um abuso de espaços vazios, seja na ausência de imagens definidas em uma tela, ou no vazio que circunda uma escultura em uma grande sala. Na música "os espaços vazios” surgem em forma de pausas, cortes ou fermatas. Na obra de Beckett, a ausência de cenários e os silêncios que interrompem momentaneamente as vozes de suas personagens, podem gerar o mesmo efeito: favorecer o clima de meditação. Not Ié um drama de ação ausente. As personagens são desencarnadas e suspensas no espaço. As palavras e frases são segmentadas. O "eu" de Not I é, talvez, a maior personagem dramática minimalista do repertório beckettiano. A Boca, protagonista da peça, ao não aceitar a sua existência, acentua o silêncio corrosivo. E o silêncio surge entre as palavras, nas entrelinhas e na forma escrita, mais explicitamente. Os pensamentos são quebrados e incompletos, e acabam por "frustrar" o espectador na expectativa de uma compreensão linear do texto dito pela Boca. Tais pensamentos, compostos por elipses de frases curtas, permitem pequenas pausas e reticências no decorrer da peça que, muitas vezes, aparentam ser drásticas, em função da falta de sequência no discurso. ${ }^{18}$ 
O silêncio, ou ausência de manifestação sonora, tem notação própria e ocupa espaços perfeitamente delimitados no tempo. Não há outras variáveis além de sua duração. Suas funções múltiplas e suas possibilidades de articulação o tornam tão importante quanto os sons. Em uma partitura de música tradicional é comum percebemos notações de pausas em forma de cortes e fermatas, entretanto, na música minimalista, os silêncios tendem a ser longos. A tela em branco de alguns artistas visuais como Frank Stella e Barnett Newman criam um espaço vazio análogo ao espaço escrito e criado por Beckett em suas peças, como sugere Batchelor. ${ }^{19}$ Assim como na peça Breath (sem tradução para o português), de 1969 - considerada a obra mais curta de Beckett e quiçá, de toda a dramaturgia ocidental - que também se apropria do silêncio para criar um espaço meditativo. Seu tempo de duração não é maior que um minuto e é construída a partir de uma imagem de lixo espalhado, precedida por dois gritos e um som constante de respiração. A rubrica indica: Um grito breve... silêncio por, aproximadamente, cinco segundos... grito como o anterior. ${ }^{20} \mathrm{O}$ fatídico silêncio, rompido apenas pelos gritos e uma respiração compassada, faz dessa peça um drama minimalista definitivo.

Em verdade, toda obra de Beckett explora o recurso do silêncio, mas há outras duas peças de seu repertório que merecem consideração pelo silêncio quase absoluto que as permeiam: Act Without Words I e II, ambas escritas em 1956. Nesses "dramatículos", à exceção da música de fundo, as palavras estão ausentes e o mínimo de movimentação é empregado, sendo valorizada cada ação física ou sonora.

Breath, que não tem movimentação alguma, nos remete à composição de John Cage, 4’33’', em que um pianista sobe ao palco, senta defronte ao piano e, num gesto cuja intenção seria a de executar a peça, aguarda o tempo que dá nome à música. Depois se levanta e caminha para fora do palco. De acordo com Paul Griffiths, o compositor curiosamente criou a sua obra inspirado em um trabalho de James Joyce, que por sua vez, sabemos, foi uma das inspirações para Beckett. A composição Roaratorio, de Cage, seria baseada no romance considerado obra-prima de Joyce, Finnegan's Wake. A peça entrelaça a tradicional música irlandesa, com o texto proveniente do romance e os sons mencionados no livro. Joyce dispensa a narrativa formal e a estrutura linguística, justamente como faz Cage ao abandonar os elementos normais de composição para imprimir sua própria estética musical. ${ }^{21}$ Apesar disso, Joyce normalmente utiliza um excesso de informações em sua criação artística, diferentemente de Cage e de Beckett, que trabalham com o mínimo de informação.

Beckett similarmente usa a mínima quantidade de material para expor a sua obra. O dramaturgo utiliza extensivamen-
19. BATCHELOR, David. Minimalismo - movimentos da arte moderna, 1999, p. 32.

20. BECKET'T, Samuel. Breath, 1970, p. 371, grifo meu.

21. GRIFFITHS, Paul E. Modern Music: A Concise History. 1994, p. 120 
te as "repetições" e os "silêncios", impedindo que seu público perceba qualquer mudança dramática ou movimento radical, induzindo-o a sintonizar com o ritmo da respiração ou do monótono discurso emitido por suas personagens e, por alguns instantes, atingir um estado meditativo. Há de se ressaltar, no entanto, que tais recursos não diminuem a força do significado das palavras nas peças de Beckett, e que princípios como o efeito da repetição ou do silêncio são traços estilísticos que fazem parte da escrita do autor, mas que podem produzir um efeito sinestésico colaborando para a compreensão de sua obra na totalidade. 


\section{Referências}

BATCHELOR, David. Minimalismo - movimentos da arte moderna. São Paulo: Cosac \& Naify, 1999.

BECKETT, Samuel. The complete dramatic works. London: Faber and Faber, 2002.

BERRETTINI, Célia. A linguagem de Beckett. São Paulo: Perspectiva, 1977.

BRATER, Enoch. Beyond Minimalism: Beckett's Last Style. New York: Oxford University Press Inc, 1987.

GRIFFITHS, Paul E. Modern Music: A Concise History. London: Thames \& Hudson; Rev Sub edition, 1994.

LEUCHS, Louisa Elena, Minimal B: Samuel Beckett and Minimal Art. Washington: The George Washington University Press, 2002.

NYMAN, Michael. Experimental music. Cage and beyond, New York: Schirmer Books. A Division of Macmillan Publishing Co., 1974.

OPPENHEIM, Lois. Samuel Beckett and the arts: music, visual arts, and non-print media. New York - London: The University of Michigan Press, 1999.

RAMOS, Marco Antonio da Silva. "O uso musical do silêncio”. Revista música, vol. 08, n⿳丷ㅡ 1/2 , São Paulo: ECA/ USP, 1997, pp. 68-129.

ROUBINE, Jean-Jacques. Introdução às grandes teorias do teatro. Trad: André Telles. Rio de Janeiro: Jorge Zahar Editor, 2003.

STRICKLAND, Edward. Minimalism: Origins. Bloomington and Indianapolis: Indiana University Press, 1993. 
